\title{
LOS SIGNIFICADOS DE CULTURA Y LOS SIGNIFICADOS DE PUEBLO. UNA HISTORIA INACABADA.
}

\author{
Honorio M. Velasco*
}

Universidad Nacional de Educación a Distancia

RESUMEN. El debate sobre el concepto de «cultura popular» está lejos de haber concluido. En realidad, es una complicación más del debate sobre el concepto de «cultura», al que se añade el del concepto de «pueblo». La historia de estos dos términos y sus cambiantes significados revela, sin embargo, algunas sugerentes implicaciones. Tras muchas de las formas de configurar la «cultura popular» hay un esquema jerarquizado de cultura que ha transmutado la diversidad cultural en diferencia o, si se quiere, en distinción y en desigualdad.

Naturalmente que cualquier planteamiento sobre la «cultura popular» remite a un debate permanente sobre la cultura. $Y$ por situarse en ese debate es oportuno decir que, para quien haya asumido el principio del relativismo cultural como un modo más que razonable de abarcar el imposible horizonte de la diversidad de las sociedades humanas, muchos de los planteamientos suscitados sobre la «cultura popular» le resultan en el fondo escandalosos. Desde una perspectiva antropológica, es decir, aquella en la que nos embarcaron Tylor, Frazer, Malinowski y otros, cultura es

* Agradezco a Gonzalo Abril, Renato Ortiz, Jesús Martín-Barbero, Francisco Cruces y Angel Diaz de Rada sus críticas y sugerencias, y a Luis Grau la anécdota sobre los «leperos». Y a los organizadores del encuentro de Almagro 1991, «Movimientos sociales y culturas populares», en donde se presentó una primera versión de este texto, su amable invitación. 
todo lo humano de todos los pueblos (humanos). Debería estas absoluta mente de más toda posibilidad de especificación que no se refiera a un sujeto colectivo cuya distintividad es no cuestionable: las sociedades humanas; según un término clásico, los «pueblos»o, si se prefiere en terminología moderna, los «grupos étnicos». Pero la entidad, límites y pertinencia de tales sujetos colectivos es algo históricamente cuestionado y cuestionable. Una fundamental contradicción es posible descubrir en el concepto de «cultura»: con él pretendemos universalidad, pero todos los pueblos proyectan sobre él su diferencia. Por lo que parece que cualquier planteamiento sobre la «cultura popular» remite indisociablemente a un debate permanente sobre el concepto de «pueblo».

Una vez logrado, no sin esfuerzo, por parte de esta sociedad que autoevalúa su modo de vida como «cultura», el reconocimiento de que cualquier otro modo de vida de cualquier otra sociedad humana es tan «cultura» como el suyo, resulta escandaloso que para referirse a un sector históricamente delimitado de esa sociedad —en este caso, y por utilizar otro término clásico, el pueblo llano- sea aún necesario atribuirle explícitamente el término de «cultura». La distintividad aquí tiene un sentido y un valor contrarios, pues, lejos de reafirmar el principio del relativismo cultural, parece implicar una insostenible diferencia.

De ese modo, «cultura popular», «cultura de élite» o «cultura de la pobreza», «cultura burguesa»y, por otro lado, también denominaciones tales como «cultura administrativa», «cultura política», etc., son o pueden ser todas o fórmulas redundantes, sin sentido, o intencionada y sospechosamente cargadas de sentido.

No es posible negar que existe una clara contradicción entre la aplicación del principio del relativismo cultural y el continuado ejercicio de diferencia o, si se quiere, de distinción que conlleva el concepto de «cultura». Como no es posible negar que la antropología ha tratado de generalizar para cualquier otra sociedad conceptos forjados en la sociedad que la ampara. Ese es uno de los dramas de esta ciencia. Y ése es el caso prototípico de su principal aportación a las ciencias sociales y humanas: el concepto de cultura.

Porque no es tan obvio, hay que decirlo: «cultura» es un término culto, un cultismo. Introducido presumiblemente en el Renacimiento, no aparece en el Tesoro de Covarrubias, pero lo usó fray Luis de León. El Diccionario de Autoridades enuncia tres acepciones: $1 .^{a}$ " la labor del campo o el ejerci-

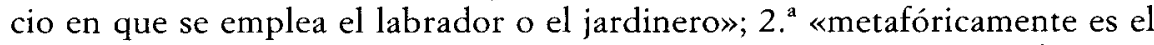
cuidado y aplicación para que alguna cosa se perfeccione, como la enseñanza en un joven, para que pueda lucir su entendimiento», y $3 .^{a}$ «vale también lo mismo que Culto en el sentido de reverencia o adoración». Si se acepta como punto de partida este desglose de significados del Diccionario de Autoridades y se recuerda el conjunto complejo y ambiguo de significados que tiene el término hoy día, habrá que concluir que se han producido 
algunas extensiones y desplazamientos metafóricos y otras extensiones y desplazamientos metonímicos.

Curiosamente, hemos llegado a emplear como término más generalizador con el que referirnos a todas las formas de vida de todos los pueblos de la Tierra un término que originariamente proviene de una sociedad agrícola y que tal sociedad utilizaba para designar el cultivo de la tierra. (En inglés y en francés, los primeros significados documentados se refieren igualmente a la agricultura, siglo XV -cfr. R. Williams, 1976; M. Imbert, 1979-.) El esfuerzo, aplicación y cuidado que se tenía como normativo en el trabajo de la tierra es el que parece haber servido de modelizador para todo otro proceso de perfeccionamiento, y en particular para la educación de los jóvenes. La metáfora de las dotes naturales que exigen un posterior ejercicio y una disciplina y esfuerzo continuados para poder llegar a ser efectivas, como exigen las semillas atención, cuidado y trabajo para fructificar, es vieja y extendida en la latinidad. (También se encuentra en inglés y en francés desde el XVI al XIX.) Es la metáfora de una sociedad agrícola que concibe a los hombres como plantas. La metáfora con la que entiende la transformación de la naturaleza en cultura. Cultura es, pues, ese proceso de cuidado y dedicación, ese perfeccionamiento. No en vano es una evidente sustantivación del participio de futuro activo latino culturus. Denota un proceso y connota su resultado. $Y$ tras este primer desplazamiento metafórico el término se fue deslizando metonímicamente hasta designar la evolución de la Humanidad. Un deslizamiento obviamente etnocéntrico que suponía que el desarrollo de la Humanidad había seguido el mismo modelo que el desarrollo de un individuo en esta sociedad. Este deslizamiento aún no es recogido por el Diccionario de Autoridades (1726), pero parece bien implícito en el siglo XVIII, de forma que, cuando el término es reelaborado por los teóricos de las Geistwissenchaften, la Kultur es difundida en Europa por oposición a la Naturaleza y designa la expresión del espíritu, del genio de un pueblo, y, asumida por Gustav Klemm, es el contenido básico de su Allgemeine Kulturgeschichte der Menschbeit (1843-1852), es decir, de la historia general de la Humanidad. Ese contenido básico incluye costumbres, artes y habilidades, la vida doméstica y pública, la religión, la ciencia y el arte. Y éso es lo que Tylor recoge y lo que el principio del relativismo relativiza hasta poder designar con él a las costumbres, artes y habilidades de cualquier pueblo. Las últimas extensiones metonímicas convirtieron la Kultur en «las culturas», en plural. Pero, evidentemente, no ha sido ésta la única cristalización de significado. Ambas extensiones han debido ir implicadas. De todo este proceso, lo más relevante tal vez sea que haya llegado finalmente a denotar el resultado y connotar el proceso.

Es decir, las extensiones y desplazamientos han dejado un campo semántico más bien complejo y relativamente confuso. R. Williams destaca tres direcciones de significado: 1) el proceso general de desarrollo intelectual, espiritual y estético; 2) la forma de vida particular, ya sea de un 
pueblo, un período o un grupo, y 3) las obras y prácticas de la actividad intelectual y específicamente artística. Pero habría que advertir que esas tres direcciones se cruzan y a veces tratan de anularse unas a otras. Parece sobre todo haber quedado consolidado en esta sociedad este último significado que alude a un dominio delimitado, un «mundo», que hemos dado en llamar «cultura» y que engloba obras y prácticas de escritores y artistas, formado a base de creaciones y reproducciones, lecturas y audiciones, interpretaciones y contemplaciones. Todo ello convertido en bienes y servicios susceptibles de apreciación, en el doble sentido de establecimiento de un precio y de atribución de un valor. Un dominio cada vez más amplio, pues trata continuamente de rescatar del olvido y del abandono materiales que se remontan a antes de la Historia y, a la vez, de anticipar formas aún no integradas en la Historia. Como dice M. Imbert (1979), está cruzado por tensiones múltiples entre la tradición y la innovación, entre el academicismo y la subversión, entre el clasicismo y el vanguardismo. Este dominio en cuanto a las obras se configura fundamentalmente a base de colecciones. Lo que acaba materializando el dominio en espacios de acumulación: museos, bibliotecas, filmotecas, etc., de forma que puede uno transitar por lo que, paradójicamente, fue algo espiritual e intangible. Y en cuanto a las prácticas, se configura fundamentalmente a base de «programas», un peculiar modo de regularizar actos y espectáculos que también tienen lugar en espacios que lo son en cierto modo de acumulación, en este caso sucesiva, en donde igualmente se materializa ese dominio en principio moral, etéreo.

Este dominio de la «cultura» ha llegado a instituirse como uno más en la vida de los pueblos añadido a los dominios ecológico, técnico, económico, político, jurídico, religioso y social... Una parcelación que es la coartada de la legitimidad de los profesionales que los controlan. Corresponde esta fragmentación en dominios a ciertas concepciones de la naturaleza humana que la presentan formada por dimensiones ordenadas en estratos (biológico, psicológico, social y cultural) (Geertz, 1987). Este deslinde de ámbitos o de dimensiones no es un simple muestrario de campos o aspectos, sino que suele suponer una ordenación jerarquizada que, a pesar de todo, reserva a la cultura posiciones periféricas o posiciones superficiales, fácilmente convertibles en superfluas.

El significado de «cultura» como dominio deslindado y, por su especial dinamicidad, supuestamente autónomo parece haber recogido tanteos significativos producidos ya en los siglos XVIII y XIX que fueron desmarcándole respecto a dos referencias opuestas: por un lado, la Naturaleza, y en ésto el concepto es heredero de la Ilustración, pero, por otro, el relieve mecánico del progreso - la máquina-, y en ésto es heredero del Romanticismo. Hay notables y sorprendentes muestras de esta doble posición en la insistencia que muestran los términos a veces usados de «cultura física», es decir, el ejercicio corporal, una de cuyas expresiones es casi caricaturesca, el 
«culturismo», y de «cultura material», que engloba todo el conjunto de productos e instrumentos cuya burda utilidad les sitúa fuera -aunque nunca completamente- del Arte.

En realidad, este significado de la cultura como conjunto de obras y prácticas de la actividad intelectual y artística es más bien moderno y su configuración como dominio autónomo puede parecer un camuflaje, pues nunca ha sido tan sociológicamente desencarnada. La complicación y el solapamiento con los otros significados de cultura antes expuestos forman parte de la entraña misma del concepto. Por un lado, nunca ha perdido del todo el sentido de proceso, de perfeccionamiento. Ha ido y sigue yendo asociada a Educación y es concebida en grados. «Ser educado» y «ser culto», «tener cultura» y «tener educación» son expresiones equivalentes y susceptibles de ser enunciadas para mostrar diferencias absolutas o graduales. Posiblemente, la equivalencia derive de la institucionalización del proceso educativo. Parece haberse tendido por parte de las instituciones de educación a exclusivizar ese proceso general que antiguamente se llamaba «cultura»y, con ello, el resultado, es decir, la cultura, ha venido siendo forjado e identificado por el modo institucionalizado de educación. Con varias consecuencias: primera, que cultura consiste esencialmente en leer y escribir, y segunda, que adquirir cultura consiste esencialmente en asimilar la información que se transfiere a través de la lectura y la escritura. Eso puede ayudar a comprender el cómo del desplazamiento metonímico del proceso al resultado. La diferenciación en grados forma parte de la estructura normativa de las instituciones de educación. Casi no es necesario añadir que la institucionalización laica, es decir, legitimada por el Estado, de la educación fue gestada con la emergencia y consolidación de las clases burguesas ni que implicó la segregación y, por lo tanto, la distinción de este proceso, de este perfeccionamiento, o, lo que es lo mismo, la desigualdad de acceso a la cultura, para otros grupos sociales, en especial para los campesinos y las clases trabajadoras. Precisamente los grupos sociales que han venido siendo englobados en ese igualmente ambiguo y complejo término de «pueblo».

No puede, sin embargo, olvidarse que, no del mismo modo pero sí con similar tendencia a como la educación significó también el proceso de aprendizaje de modos y maneras distinguidas o simplemente prudentes y que se supone ha ocurrido con el trato con gentes de condición o a través de viajes y experiencias variadas, la cultura ha significado una especie de conocimiento general más allá del ámbito académico que incluye formas y costumbres hábitos y habilidades adguirido con la ampliación del círculo de relación social y experiencia de acontecimientos que dan los viajes (vividos al modo burgués). Pese a la exclusivización que las instituciones educativas hayan podido pretender para la transmisión de la cultura, este término parece haber mantenido siempre un sentido generalizador.

Otra dirección de complicación de significado es la que ha venido 
siendo intensificada a la vez que se producía en la sociedad europea la moderna construcción del concepto de hombre, que ha exigido tanto el reconocimiento interno de grupos y sectores sociales marginados de uno $\mathrm{u}$ otro modo (mujeres, niños, disminuidos físicos o mentales, etc.) como el paradójico reconocimiento de las diversas sociedades humanas, en la mayoría de las veces a costa de su colonización. En ambos casos, la cultura es atribuida distintivamente a un sujeto colectivo, el «pueblo», los «pueblos», y ha estado tanto en el núcleo legitimador de la abolición de la esclavitud y de las desigualdades sociales como en el núcleo legitimador de los nacionalismos y las luchas contra los imperialismos. Cultura ha sido, entre otras cosas, el antídoto ideológico del envenenado concepto de Raza y, también, el estandarte ideológico de los movimientos de emancipación política. Incluso ha sido el referente revolucionario de los movimientos juveniles de los años sesenta: la contracultura.

Las complicaciones sociológicas y antropológicas de la cultura son tales que exigen la anulación de cualquier significado que restrinja su contenido a «las obras y prácticas de la actividad intelectual y artística». Se entiende que la cultura da consistencia a la distintividad de un «pueblo», un sujeto colectivo que se expresa a través de ella diferenciadamente. No puede ser, por tanto, un simple dominio relativamente autónomo ni tampoco, finalmente, puede ser un proceso diferenciado en grados. La diferencia que trabaja la cultura no es cuestión de grados, es cuestión de «pueblos», es decir, de todos definidos socialmente. Sorprendentemente, fue Herder quien a fines del xvin introdujo la innovación decisiva de hablar de «culturas» en plural, aunque la innovación no se adoptó más que a fines del XIX. Más allá de las formas académicas, más allá de las formas sociales, cultura es una forma de vivir. $Y$ engloba todo lo que Tylor acabó especificando, es decir, «el conocimiento, las creencias, las artes, la moral, las leyes, las costumbres y cualesquiera otras aptitudes y hábitos adquiridos por el hombre como miembro de la sociedad». La disolución de la supuesta autonomía de este dominio proviene de la fundamentación de la cultura en la condición de miembro de una sociedad. Atribuible, por tanto, a todos los miembros de una sociedad determinada y atribuible a todos los que son miembros de alguna sociedad. No es «cultura» lo que distingue a algunos, sino lo que distingue a todos. No hay tal dominio autónomo que, en realidad, oculta una segregación injustificable. No hay «cultura» sin «pueblo», como no hay «pueblo» sin «cultura».

La historia de los significados de los términos «pueblo» y «popular» no es menos compleja. En la Edad Media, «pueblo» tenía en castellano al menos tres significados: el de conjunto de gente indiferenciada, el de 
conjunto de gente como entidad política y el de localidad habitada. «Popular» es, sin embargo, otro cultismo, introducido por los humanistas (Corominas). En el siglo xvill, el Diccionario de Autoridades enuncia como primera acepción de «pueblo» la de «lugar o ciudad poblada por gente»; en segundo lugar, la de «conjunto de gentes que habitan el lugar», y en tercero, la de «gente común y ordinaria de alguna ciudad o población, a distinción de los Nobles». Hay constancia, además, de otra acepción que alude a los «pueblos» como conjuntos de gentes que ocupan cualquier lugar en la Tierra. El término tiene en castellano peculiaridades que no son comunes a otras lenguas europeas: una, el desplazamiento metonímico que identifica el lugar habitado y la gente que lo habita como «pueblo», y dos, la diferenciación no sólo en el tamaño, sino en el implicado estilo de vida entre ciudad y campo, que reserva para los que habitan en éste la caracterización de «ser de pueblo». De todos modos, la calificación de «popular» recogió los matices de la distinción sociológica (posiblemente gestados por los intelectuales franceses desde fines del XVII a mediados del XIX, frente a la idea más unitaria que se trasluce en el Volk alemán —cfr. M. Imbert, 1979-) y no los de la diferenciación territorial, si bien es posible percibir algunas connotaciones de ésta.

Hay un cierto paralelismo en la historia de las complejidades semánticas de «cultura» y de «pueblo», aunque con desplazamientos hacia posiciones opuestas. Ambos son términos con capacidad globalizadora, pero «cultura» ha llegado a ser restringido hasta designar las obras y prácticas de grupos o individuos selectos. Selectos por haber recibido educación o por haber desarrollado sus capacidades. Educación o desarrollo que parece haber sido más posible en las ciudades o en el seno y al amparo de las clases altas o burguesas. Mientras que «pueblo» ha llegado a ser desplazado hasta designar precisamente la gente no selecta, no cultivada, la gente común u ordinaria; al fin y al cabo, el «pueblo llano», las clases bajas -obsérvense las metáforas espaciales que indican distinción (alto) y no distinción (llano, bajo)_, y por otro lado o por el mismo, a la gente del campo.

Es tentador tratar de enlazar ambos desplazamientos, el de cultura hacia lo distinguido, el de pueblo hacia lo común. Tal vez no se trate de una simple coincidencia $y$, aunque en principio no tendrían por qué estar interrelacionados, presentan importantes complicaciones semánticas. Sería posible enunciar como sugerencia que en la medida en que la «cultura» haya sido un dominio fomentado para la distinción social, presumiblemente más por la burguesía, el «pueblo» y lo «popular» se ha delimitado como el marco referencial respecto al cual señalar esa distinción.

Shiach (1989) ha trazado la historia de los significados de «popular» en el pensamiento inglés. $\mathrm{Y}$ como dato es bastante más de lo que puede obtenerse de los distintos diccionarios castellanos, que se limitan a indicar que «popular» es «lo que corresponde al pueblo». Como antes he indica- 
do, el término «popular» es también un cultismo. Comenzó a emplearse en el siglo XVI en escritos de tipo legal o político y designando al pueblo como una unidad política constituida. La «acción popular» se entiende como aquella que se enuncia de la gente en conjunto o que es accesible a cualquiera. A mediados del siglo xviII, expresiones como «gobierno popular» valían tanto como un gobierno que cuenta con el consentimiento del pueblo, un gobierno que atiende a los intereses del pueblo o un gobierno que incita a desconfianza y temor. Durante el siglo XVIII, «popular» adopta referencias a los «plebeyos» y, a comienzos del XIX, ya aparece con connotaciones negativas que aluden al caos y la vulgaridad. El sentido de accesibilidad cobra especial relieve cuando el término «popular» empieza a asociarse a actividades que hoy reconocemos como «culturales», a fines del xvw. Claramente, el progreso tecnológico y la extensión educativa que hizo algo más accesible la letra impresa a sectores sociales antes analfabetos permitió la producción de cosas tales como «prensa popular»; un ejemplo primero serían los pliegos de cordel y, más tarde, las «bibliotecas populares», como la Bibliothèque bleue. La accesibilidad, sin embargo, no eliminó connotaciones negativas de lo popular, sino que, si acaso, peyorizó las producciones culturales masivas que atendían a los dudosos gustos del pueblo, de la misma manera que anteriormente la acción política tendente a ganarse «favor del pueblo» había sido tan ambiguamente considerada como condescendiente y manipuladora. «Popularización» ha acabado siendo sinónimo de divulgación, de vulgarización, naturalmente posibles gracias a una mayor accesibilidad, pero con un cierto sentido adherido de rebajamiento, de envilecimiento.

En el XIX se produce, sobre todo, una importante torsión en el significado de «pueblo». Puede ser otra coincidencia, pero es necesario subrayar que aquellos pensadores alemanes que vigorizaron el concepto de «cultura» se sintieron fascinados por un concepto idealizado de «pueblo», una entidad social que representaba la entraña de una Nación. Herder, que se sepa, fue el primero en utilizar la expresión «cultura popular», Kultur des Volkes. El uso de esta expresión tal vez fue ocasional y el contenido de esta cultura fue en principio limitado, pero acabó siendo forjado con Von Arnim y los hermanos Grimm un término singular, Volkskunde, cuyo contenido se fue llenando con canciones, mitos, leyendas, danzas, música y, finalmente, con refranes, adivinanzas, objetos artesanos, costumbres y fiestas. Es interesante indicar que antes de que cristalizara el término Volkskunde se habló primero de «canciones populares». Ese era el tema sobre el que Herder llegó a utilizar la expresión «cultura popular». A continuación, de «cuentos y leyendas populares», ya antes de los Grimm pero sobre todo con ellos, y, luego y con la aceptación del Volkskunde, de «juegos populares», «arte popular», «costumbres populares», «religión popular», etc.

Podría ser útil subrayar de entrada dos aspectos. Primero, que, aun habiéndolo apuntado Herder, el término que fraguó para designar todo 
este contenido cultural vinculado al pueblo, y al espíritu político que se transparentaba en forma de Nación, no incluía en principio propiamente la palabra «cultura». Del mismo modo que tampoco la incluía el otro término, este inglés, que tuvo más fortuna y acabó siendo aceptado universalmente, folklore. La carta de Ambrose Merton, seudónimo de William John Thoms, publicada en el Atheneum el 22 de agosto de 1846, en donde reclama el honor de haber introducido ese término - en realidad pretendía traducir adecuadamente el de Volkskunde-, comienza así: «Sus páginas me han dado tantas muestras del interés que usted tiene hacia lo que en Inglaterra denominamos antigüedades populares o literatura popular (aunque de paso diremos que es más lore que literatura y que podría llamarse más correctamente mediante el compuesto sajón folklore: the lore of the folk)...» Y cuando Antonio Machado, a comienzos de la década de los ochenta del Xix, trata de promover en España el folklore, entendió que se refería al «saber y las tradiciones populares» (Guichot, 1984). Es posible percibir en unos y otros una cierta resistencia ante la identificación de lore con literatura o con ciencia. Es evidente que ni en tiempos de Thoms en Inglaterra ni en los de Machado en España el término «cultura» había sido aceptado con sus significados modernos, pero intento sugerir que Tylor pudo configurar estos modernos significados de «cultura» antes expuestos en buena medida gracias al activo desarrollo del Volkskunde y del Folklore y al omnicomprensivo contenido del que se les fue dotando. Es buena prueba de ello que, a comienzos del siglo $\mathrm{xx}$-cuando ya este moderno significado de «cultura» estaba configurado-, Burne, Zingarelli y otros folkloristas entendieron que la mejor traducción de lore era precisamente «cultura» (Corso, 1963).

Y segundo, con Herder, pero sobre todo con el Volskunde de Von Arnim y los hermanos Grimm, esta «cultura popular» contribuyó eficazmente a la construcción de ese «pueblo» idealizado que imaginaron emergiendo desde las profundidades de la Historia (o tal vez de la Naturaleza) para constituirse irrefrenablemente como Nación. Uno de los argumentos más repetidos por los impulsores del folklore en los distintos países europeos y americanos ha sido el de contribuir con él a un hondo conocimiento del pueblo y poder mostrar a través de él el verdadero espíritu de ese pueblo. La toma de conciencia de un pueblo como Nación ha estado desde entonces alimentada en buena medida con argumentos proporcionados por la «cultura popular», más exactamente por contenidos específicos del folklore. He intentado explicar en otro lugar (Velasco, 1990) que la obra de los folkloristas consistió fundamentalmente en hacer colecciones, y de qué modo los criterios metodológicos seguidos al hacer una colección son de una sorprendente eficacia a la hora de dar entidad a ese sujeto colectivo que llamaban «pueblo». Pero es el momento de revisar quién era ese «pueblo» que imaginaban y con qué «cultura» lo imaginaron.

Uno de los capítulos programáticos de todo manual de folklore está 
dedicado necesariamente a la identificación de «pueblo». Como se habrá advertido en la mencionada carta de Thoms, el folklore se presentó como continuador de los estudios sobre antigüedades, según se decía entonces; sobre tradiciones, según el término que finalmente llegó a imponerse, y su estudio fue justificado como una historia menor. Reproduzco a R. Corso: «Una historia que hubiera permanecido en la sombra hasta entonces, la historia de los humildes, de los ignorantes, de los olvidados, de los sin nombre, la historia de agricultores, pastores, obreros, mujerzuelas y niños, la historia del verdadero pueblo: historia política, literaria, natural, religiosa y de las costumbres» (Corso, 1963). Para muchos folkloristas, la cultura popular es cultura tradicional y el folklore un complemento de la Historia. La imagen de «pueblo» que aquí aparece es precisamente la de los sectores sociales no considerados sujetos de la Historia formal y, lo que es más importante, considerados continuadores de tradiciones previas a la propia Historia y permanentes dentro de ella. Esta imagen de «pueblo» incluye la concepción de un sujeto colectivo permanente en el tiempo, cuya permanencia se muestra precisamente en su «cultura», en sus tradiciones. La transferencia del carácter de permanente entre el pueblo y la cultura que se delata en el concepto de «tradición» ha quedado en evidencia al haber podido mostrar estudios más bien recientes que muchas tradiciones en realidad fueron inventadas. Los propios folkloristas contribuyeron a ello (Hobsbawm y Range, 1975).

El concepto de tradición, como el concepto de cultura, denota un proceso y connota un resultado. Como proceso, cuando se aplica a lo popular, asume un modo de comunicación, la oralidad, inequívocamente paralelo y diferenciado del modo de comunicación institucionalizado en y por las instituciones educativas $y$, por tanto, característico de los sectores sociales que no han tenido acceso a ellas. Pero, además, es un proceso normativo que es regido por el valor de inalterabilidad que tiene lo recibido del pasado, lo que implicaba, por otro lado, inmovilismo, primitivismo. La asunción del paradigma evolucionista hizo evidente la paradoja, pues suponía la equivalencia entre las clases humildes y los pueblos primitivos, de modo que Lubbock llegó a decir que «el pueblo es un gran salvaje perdido en el seno de la civilización». Tal equivalencia se hizo incómoda para los cultivadores del folklore, que trataron denodadamente de liberar la imagen de «pueblo» que estaban construyendo de perfiles sombríos o amenazadores. Algunos, como R. Corso, rechazaron que el «pueblo» del saber popular, de la cultura popular, fueran las clases pobres o el populacho y se dirigieron a los rústicos, los campesinos, como «custodios de las puras y vírgenes tradiciones patrias». Otros, como Luis de Hoyos (1947), prefirieron una referencia un tanto más abstracta pero no menos reveladora. Las esencias del folklore estaban en lo tradicional, lo popular (un concepto intuitivo que permita reconocer que «pueblo» es tanto un labriego como un magistrado o una duquesa supersticiosos), lo anónimo, que se 
dirían esenciales, y otras cuatro características complementarias pero no menos esencias, a saber: lo regional, lo racial, lo femenino y lo infantil. El «pueblo» que engloba todas estas «esencias» difumina, suaviza cualquiera de los posibles rictus de perversión que pudieran aparecer en ese sujeto colectivo. La imagen del pueblo que se dibuja reelabora los nuevos significados y recoge algunos de los viejos significados castellanos. Es tradicional por lo permanente, no tiene entidad política, es el común, el fondo anónimo, porque tiene más relieve como conjunto que como agregación de individuos y porque el anonimato es la mejor expresión de la popularización. (Se entiende que un posible autor de una obra cultural habría logrado la máxima satisfacción cuando ésta hubiera sido tan plenamente asumida por el pueblo que la tomara como suya propia.) Está circunscrito a un lugar, a un territorio, y se entiende que el pueblo está tan ligado genéricamente a la tierra que ocupa que hasta procede de ella. «Raíces» es la metáfora con la que se designa a la «cultura popular». (Intencionadamente, Luis de Hoyos elige la delimitación territorial de lo regional, evitando toda posibilidad de proporcionar justificación a las reivindicaciones nacionalistas para los territorios que integran la nación española.) Incluye la categoría de lo racial guardándose de identificar raza y pueblo o cultura, pero intentando fundamentar las diferencias evidentes entre, por ejemplo, el alma gallega y el alma levantina en algo más que el ambiente y la tierra. Resabios spencerianos que, además, son consonantes con significados luego dramáticamente explícitos en el Volkskunde alemán, aunque menos en el Folklore inglés. Los otros dos perfiles, el de lo femenino y lo infantil, son casi ingenuos. Aluden a sectores sociales que se supone más insertos en la vida tradicional, pero son sintomáticos tanto de lo que muchos folkloristas entendían por «cultura popular» como de las prácticas culturales que atribuían a mujeres y niños.

Esta era la imagen del pueblo, con la pretensión de ser una imagen del auténtico pueblo, una imagen construida con y por medio de la «cultura», desde entonces «cultura popular». Pero, en realidad, el folklore, la cultura popular, fue descubierta por algunos intelectuales europeos cuando creían que estaba a punto de desaparecer. Una situación paradójicamente constante desde entonces, si se recuerda que ha pasado siglo y medio y sigue estando a punto de desaparecer. Su labor primera y explícita respecto a ella fue recuperarla. Una labor singular si se contrasta con lo que parece debiera ser la labor exigida a practicantes de la cultura (se entiende no popular), que es - por continuar con los significados antes desglosadoscontribuir a su desarrollo, a su perfeccionamiento. Pero resulta más revelador indicar que quienes la promovieron, quienes la descubrieron -bien puede decirse la inventaron-, no pertenecían propiamente a los sectores sociales donde la hallaron, las clases populares y, sobre todo, los campesinos, ni destinaron su obra propiamente a esos sectores sociales de quienes la recuperaron. 
Antonio Machado tuvo la revelación, leyendo la Revue Celtique en 1880, que lo que el grupo sevillano formado en torno a Federico de Castro había estado haciendo era folklore (Guichot, 1984). Pero quienes realmente descubrieron que tenían folklore sin saberlo fueron las criadas, criados, jornaleros, las gentes de los barrios y la gente del campo, a quienes ese grupo acudía en busca de coplas, romances, cantares, cuentos, adivinanzas, juegos, supersticiones, etc. Muchos descubrieron con asombro -y posiblemente con incredulidad y desconfianza- que tenían «cultura» sin saberlo, y recelaron del interés que aquellos a quienes tenían por «educados» mostraron por asuntos demasiado conocidos o demasiado intrascendentes para ellos mismos. Más tarde y del mismo modo, los oficiales y aprendices de oficios diversos descubrieron que hacían Artesanía sin saberlo, precisamente cuando la Revolución Industrial había convertido su proceso de trabajo y sus productos en residuales. Y de la misma manera que hombres y mujeres de distintas localidades descubrieron que sus vestidos eran «trajes regionales», precisamente cuando la industria textil necesitó de la ampliación de mercados para enjugar costes de inversión y mantener beneficios, proporcionando telas a precios accesibles y homogeneizando modas a base de facilitar patrones reproducibles y presentándolas por medio de figurines idealizados que aludian a estilos de vida más deseables.

Las costumbres, danzas, canciones, cuentos, etc., de las clases populares fueron recuperadas a la vez que se estaban alentando, extendiendo e implantando cambios sociales que tendian a anularlas o sustituirlas. Adquirieron, así y entonces, la categoría de «cultura popular». La cultura popular fue inventada por la Modernidad e inmediatamente absorbida por ella. Su recuperación no era estrictamente tal. Consistió fundamentalmente en un tratamiento «cultural», es decir, en pasar a colecciones y museos, un conocimiento inventariable y patrimonial. Como diría Bourdieu, el tratamiento consistió en su transformación en capital cultural. Los fines de esa recuperación, como ha subrayado Shiach (1989), tenían más que ver con problemas sociales y políticos de las clases burguesas que con cuestiones importantes para aquellos que las proporcionaron: la propia construcción de una imagen idealizada de "pueblo», que pudiera ser presentada como el sujeto colectivo legítimo reivindicador de una Nación, es tal vez el fin más caracterizado, pero no el único, al que pudo contribuir. P. Burke (1978) recuerda que la idea de «nación» fue gestada y gestionada por los intelectuales y fue impuesta al «pueblo» con el que querían identificarse.

Es una consecuencia, no del todo accesoria, de todo esto que quienes acometieron el estudio de la «cultura popular» se convirtieron literalmente en mediadores (incluida la posibilidad de haber sido también manipuladores). Uno de los rasgos de esta mediación es que tales obras se les atribuyeron a ellos. Los cuentos que recogieron los hermanos Grimm son citados como «de los hermanos Grimm», y lo mismo los cuentos de Perrault, etc. 
No se trata exactamente de una autoría usurpada, sino de que el contexto en el que y para el que fueron publicados no tenía otro modo de acoger una obra «cultural». Además, la presentación impresa o plástica de todos estos materiales siguió, evidentemente, los cánones establecidos de las obras «culturales», lo que exigió la selección, tratamiento y «transformación», a veces expresamente contradictoria con el propio mensaje de espontaneidad y naturalidad popular que deseaban transmitir. Es posible, pues, que la categoría de «cultura» que adquirió la cultura popular se deba no poco a la reelaboración de sus recopiladores.

Pese a todo, entre los significados modernos de «lo popular» parecen haber ido prevaleciendo aquellos, por otra parte lo bastante viejos como para encontrarse también en el uso de los siglos XVI y XVII, como demuestra Shiach (1989), que lo asocian a lo que está ampliamente extendido y a lo que recibe el favor, la aceptación y el aplauso del «público en general», es decir, aquellos significados que se recogen en la sustantivación de la cualidad de ser popular: «la popularidad». Un término cuyo significado actualmente reconocido no aparece en los diccionarios hasta el siglo xx. (Como término aparece en realidad antes, en diccionarios como el de Terreros, pero se hace equivaler a «vulgaridad».) Un término característicamente sociológico que se aplica tanto a personas (más bien, y por serlo, «personajes»), a artículos, objetos o mercancías como a prácticas, usos y comportamientos. No es, como ninguno de los viejos significados de lo «popular», un término simplemente descriptivo, sino que tiene indudables connotaciones axiológicas, no exentas de los mismos ribetes de ambigüedad que tenían los viejos significados de lo «popular». Se trata de una cualidad susceptible de incremento o de disminución y, además, mensurable, a través de encuestas o mediante el uso de determinados indicadores; p. ej., registros de ventas. Estrechamente asociada a la acción de los medios de comunicación de masas, objeto de manipulación por parte de agentes y agencias especializadas (publicidad, relaciones públicas, asesorías de imagen...), puede generarse, sin embargo, de forma autónoma, no dirigida, pues en esencia se refiere al modo y grado de recepción por parte de una audiencia, un público. La popularidad parece ser, más que otra cosa, una cualidad construida comunicativamente, es decir, dependiente del carácter comunicativo de la acción social. Aunque puede implicar también valoraciones de mimetismo, credulidad, ingenuidad, superficialidad, dependencia, falta de gusto, etc., es claro objetivo de determinadas instituciones políticas o de empresas económicas y se considera correspondiente a una situación de poder o que conlleva adquisición de poder.

El «pueblo» que aparece bajo el término de popularidad tiene la imagen de «público», pero no es mero receptor pasivo, pues la popularidad se entiende como una adhesión, una vinculación activa, y el ejercicio de la popularidad como una interacción. En cierto sentido, esta caracterización del «pueblo» como «público» es una especie de desnaturalización, engaño- 
samente descargada de connotaciones políticas — pues no es difícil contemplar el «populismo» como una buscada transformación del «pueblo» en «público»- y aparentemente apropiada para referirse a formas culturales, pues es el «público» la audiencia de un artista, ya sea éste creador o mero intérprete. Pero, curiosamente, resulta difícil reconocer bajo estos significados modernamente prevalentes qué es «cultura popular», salvo que se entienda por ella algo similar a lo que suele llamarse cultura «general», un nuevo término menos próximo de lo que pudiera parecer al concepto omnicomprensivo de «cultura», definitivamente homogéneo y que, sorprendentemente, puede ser incluso normativo.

La deriva de significación de lo «popular» hacia lo que indica el término «popularidad» no parece haberse desprendido del todo de referencias al «pueblo llano», pero el concepto de «público» parece implicar indiferencia respecto a si es una unidad social distintiva o un simple agregado de individuos casualmente coincidentes en gustos o intereses. Esta es, posiblemente, la razón por la que es difícil reconocer bajo estos significados a qué puede referirse entonces la «cultura popular». Hay también otras razones, pero en realidad hablan de la complejidad (y de la confusión) y de la multiplicidad de facetas que tiene la cultura en las sociedades modernas.

Ya desde finales del xIX y durante el siglo Xx, el término folklore ha ido conviviendo, aunque no del todo confundiéndose, con otros términos afines, cristalizados después. (Los libros de García Canclini, 1982 y 1990; Muchembled, 1978; De Certeau, 1979 y 1980; Martín-Barbero, 1985, y otros hacen innecesaria una exposición detallada de ello, pero por contribuir al debate añadiría algunas ideas.) El propio término «cultura popular» entre ellos, el de «cultura tradicional»y, además, el de «cultura de masas», el de «cultura de los trabajadores» y, lo que es más sorprendente, el de «cultura folk». Todo esto a la vez que el concepto de cultura, con cualquiera de sus matices, ha permanecido no sólo casi incólume, aunque múltiplemente especificado, sino que se ha ido enriqueciendo y a la vez justificando a quienes la invocan y la cultivan. A nadie se le oculta que, en los ambientes científicos europeos, el folklore ha ido cargándose de connotaciones tan peyorativas que ha acabado por utilizarse para designar precisamente lo anticientífico. Un enemigo de la ciencia, sin embargo, bastante inocente. Buscar una explicación convincente a esta devaluación no es tarea sencilla. Recuérdese que folklore es tanto el conjunto de prácticas y obras de los pueblos tradicionales como el discurso sobre ellas. ¿Dónde están las razones de su devaluación? ¿En el carácter intrascendente de esas prácticas y obras, por otro lado tan culturales como cualesquiera otras; en el ambiguo valor de la tradición en el que se amparan y que reproducen; en 
la condición marginal de los sectores sociales a los que en el fondo se alude eufemísticamente como «pueblos tradicionales»?; ¿o en la reconocida falta de rigor del discurso de los folkloristas; en la imposible exclusivización del dominio que delimitaron, de forma que nunca ha dejado de ser campo libre para entusiastas y amateurs; en la manipulación política que ellos mismos fomentaron, puesto que creían contribuir con su discurso a intensificar el amor a la patria? El propio término de «cultura popular», y naturalmente el de «cultura folk», o bien los de «cultura oral», «cultura tradicional», «cultura expresiva», se han presentado como fórmulas sustitutivas para tratar de lavar la cara al denigrado folklore, por dos métodos: o cubriendo más específicamente parcelas más aceptables, según las diversas demandas del mercado cultural, del mercado turístico o de la oportunidad política (canción, danza o fiesta); o asumiendo reivindicaciones activas del sujeto colectivo llamado «pueblo» o «pueblos»y transformando determinadas prácticas o productos culturales en armas de identidad. Todas las razones antes reseñadas y las que pudieran sumarse pudieran ser relativamente convincentes, pero en realidad no abordan el núcleo de la cuestión, que no es otro que el esquema complejamente jerarquizado con el que las sociedades modernas conciben la cultura. La denigración del folklore no es más que un ejemplo, bien ilustrativo, de cómo trabaja ese esquema.

Lo que este esquema jerarquizado con el que se concibe la cultura asume es la estrecha vinculación de la cultura con el poder. Como dice P. Bourdieu (1978), «hablar de cultura popular es hablar de política», y de economía, se entiende. Más radicalmente enunciado, habría que decir que, pese al espejismo de los dominios autónomos, la cultura siempre habla desde sí misma. La primera de las concreciones de ese esquema complejamente jerarquizado es la que enfrenta «cultura dominante» y «cultura subalterna» insertas en una relación dialéctica de clases. Habría que reconocer de entrada que primero fue enunciada (y denunciada) y convertida en superestructura ideológica, lo que aproximadamente ha devenido en «cultura dominante» (Marx y Engels, La ideologia alemana), «simbólica dominante» u otras denominaciones, continuamente desenmascaradas después como «cultura capitalista», «cultura burguesa», reelaboradas más tarde para seguir siendo desenmascaradas como «cultura imperialista», «cultura occidental», «cultura de las mayorías», «cultura patriarcal», etc. Todo ello da idea de las complejas ramificaciones del esquema jerarquizado. Parece haber tras todas estas culturas denunciadas un doble postulado asumido: el de la coextensión semántica entre ideología y cultura y el de la pretensión de instituirse como una única, homogénea y universal cultura.

Una vez establecida la existencia y complicidad de la cultura dominante con las relaciones de explotación de las clases trabajadoras e identificado inequívocamente el pueblo con éstas, el pensamiento marxista parece haber compartido el postulado de una única, homogénea y universal cultura que sólo sería popular cuando el pueblo arrebatara a las clases burguesas 
las condiciones de producción y reproducción de ella. Pero se traslucía una consecuencia más bien intolerable, la atribución de cultura que podía de hecho hacérsele al pueblo era de carencia. El esquema jerarquizado, sin embargo, se diseñó más tarde cuando, en los Cuadernos de la cárcel, Antonio Gramsci $(1974,1977)$ alumbró las claves de la «cultura popular», reconociendo la capacidad del pueblo de haber generado desde sus condiciones de trabajo y de vida formas específicas de representación, reproducción y reelaboración simbólica de sus relaciones sociales (Bronzini, 1980). Esta supuso, entre otras cosas, una forma de reevaluar el folklore como cultura de las clases subalternas, una cultura de contestación, como más tarde desarrollaron Cirese (1973) y Lombardi Satriani (1978).

El esquema jerarquizado con el que se concibe la cultura tiene otro perfil, al que parece haber sido más sensible parte del pensamiento francés y anglosajón, el que enfrenta a la «cultura de élite» y la «cultura de masas». En este caso está casi de más indicar que también fue, lógicamente, anterior el reconocimiento de una cultura de élite, pues el reconocimiento de una cultura de masas se entiende como flujo unilateral y más bien degradado de la cultura de élite. Naturalmente que este esquema jerarquizado asume como postulado la pretensión de una única, homogénea y universal cultura, pero aún más asume el postulado de un dominio cultural autónomo que incluso puede ser presentado como objeto de culto, por lo que la «cultura de masas» viene a ser casi una profanación inevitable. Bien parece que con la obligación de incluir el consumo de cultura como un elemento sustantivo dentro de ella, el perfil de esquema jerarquizado que se dibuja es casi cínico.

Tal vez no sea el mismo perfil de esquema jerarquizado el que se insinúa con la diferenciación entre «cultura cultivada» y «cultura popular», y especialmente en los matices que emplea la oposición «formal» («oficial») e «informal» para caracterizarlas, respectivamente. Adopta la «cultura cultivada» o «formal» una configuración institucional que, curiosamente, se reconoce legítimamente preeminente ante lo «informal», lo «popular», aunque históricamente posterior a esto, pues suele ser presentada como un indicador de progreso. Lo revelador de este perfil es que toda concepción de la cultura que integra un esquema jerarquizado asume que dicho esquema tiene algún fundamento evolutivo. El término de Civilización se acaba cruzando con el de Cultura para ilustrar que la cultura dominante, de élite o cultivada, es una necesaria superación de la cultura popular, o ésta una, intencionada o no, degeneración de aquélla. Sin embargo, el carácter institucional que adopta la cultura cultivada es también su paradójico punto débil, pues si, por un lado, la hace legítimamente reproducible, por el otro, se entiende que la acaba rutinizando, esclerotizando.

Un esquema jerarquizdo de la cultura aparece con otros tantos perfiles cuantos sean los campos o ámbitos del poder que invariablemente disocia a 
quienes lo tienen y a quienes carecen de él. Los movimientos feministas, los movimientos juveniles, tal vez pronto los movimientos de jubilados en las sociedades llamadas avanzadas y, en general, todos los sectores ruda o sutilmente marginados parecen haber desarrollado respectivos perfiles de un esquema jerarquizado de la cultura reelaborando alguno de los perfiles anteriormente expuestos.

Hay otro perfil más del esquema jerarquizado en la comprensión de la cultura, ése desde el que se distingue entre «cultura de la mayoría»y «culturas de las minorías», entre «cultura occidental» y «culturas del tercer mundo», entre «cultura imperialista» $\mathrm{y}$ «culturas colonizadas», «cultura del centro»y «culturas de la periferia», etc., que es en realidad múltiple. En el nivel superior del esquema hay una concepción única, homogénea y universal de la cultura. En el nivel inferior hay diversas, diferentes culturas, de diversos, diferentes pueblos. Este perfil de esquema jerarquizado revela algo que también se insinúa en el resto de perfiles. La pretensión de homogeneidad, de universalidad, niega la diversidad que se le opone.

Se han mostrado desde hace tiempo sugerentes críticas a todo esquema jerarquizado de la cultura. García Canclini (1980) aludía a que la concepción en «niveles» que se apreciaba en Gramsci y Cirese es demasiado estática y acaba formulando una oposición maniquea entre las culturas hegemónicas y las subalternas. La crítica de Bourdieu (1988) es más sutil y más demoledora. Una paradoja irresoluble enmaraña a quienes se distinguen con la «cultura popular». Si la reivindican como resistencia están afirmando precisamente a aquello que la constituye como «popular», y si la abandonan ha de ser por sumisión para apropiarse de aquello que la definía como «popular».

Otra crítica más a todos los perfiles de un esquema jerarquizado en la concepción de la cultura está en haber transformado la diversidad en diferencia, en distinción o en desigualdad. La paradoja formulada por Bourdieu es, curiosamente, el insospechado desarrollo al que ha conducido aquella primera contradicción que inmovilizó a los intelectuales progresistas del XIX que descubrieron la «cultura popular»: comprometidos con un cambio social y una renovación en las ideas, se habian adherido firmemente al Evolucionismo, que les llevó a reconocer las formas culturales en el «pueblo» sólo como supervivencias.

Esta contradicción tiene otros enunciados: el «pueblo» al que idealizaron pasó a ser un «pueblo» homogéneo. Convirtieron la diversidad cultural en diferencia, los «pueblos» en el «pueblo». Es como si de los dos viejos sentidos castellanos de «pueblo», uno, el que asocia metonímicamente gente y tierra, el que marca la diversidad y es usado para identificación mutua, hubiera quedado difuminado. Y a su costa se hubiera extendido el otro, ese que marca la diferencia de ser de ciudad. El no serlo queda entonces generalizado, homogeneizado en «ser de pueblo». La confrontación entre la diversidad y la homogeneización se aprecia bien en un chiste 
que puede ser viejo pero que hoy es atribuido a los de Lepe y que ilustra casi agriamente esto. Un viajero que pasó por Lepe correspondía al humor que derrochaban sus habitantes con expresiones tales como: «hay que ver qué gente más graciosa», «qué gente más divertida», «qué gente más salada». Hasta que uno le respondió: «Mire uzté, zeñó, nozotro no zemo "gente", zemo “leperos".»

Este chiste tiene numerosas lecturas. Incluso puede ser un ejemplo más de esquema jerarquizado de la cultura, pero también pone en evidencia el drama, la contradicción que envolvió y envuelve a muchos de los descubridores y promotores de la «cultura popular». Su reconocimiento como cultura fue a costa de disolver su diversidad. Quienes descubrieron y quienes descubren la «cultura popular» eran y son en realidad mediadores que configuran o contribuyen a dibujar una imagen de «pueblo» a veces idealizada, otras miserable (Passeron); a veces atribuyéndole protagonismos, otras dándole un mero papel de espectador ingenuo o indiferente, pero en todo caso homogeneizándole, pues la mediación se hace asumiendo los términos y procedimientos de una única y superior cultura. Por eso casi siempre el drama ha estado no sólo en tener que legitimar la mediación, sino también y sorprendentemente en hacer obligada la participación, es decir, en tener que exigir o inducir a que el «pueblo», los «pueblos», se comporten de acuerdo a la imagen que de ellos han forjado los mediadores.

\section{BIBLIOGRAFIA}

Academia Española (1969): Diccionario de Autoridades (1726), edición facsímil, Editorial Gredos, Madrid.

Bourdilu, P. (1988): Cosas dichas (1987), Gedisa, Buenos Aires.

BRozini, G. B. (1980): Cultura popolare. Dielettica e contestualità, Dedalo Libri, Bari.

Bunke, P. (1991): La cultura popular en la Europa moderna (1978), Alianza Editorial, Madrid.

Cirese, A. M. (1873): Cultura egemonica e cultura subalterne, Palumbo, Palermo.

Corominas, J. (1978): Diccionario crítico-étimológico de la lengua española, Editorial Gredos, Madrid.

Corso, R. (1966): El Folklore (1953), Eudeba, Buenos Aires.

Covarrubias, S. (1989): Tesoro de la lengua castellana o española (1611), reimpresión a cargo de Martín de Riquer, Editorial Alta Fulla, Barcelona.

De Certenu, M., et al. (1979): Las Cultures populaires, Privat, París.

- (1980): L'invention du quotidien. Arts de faire, UGE, París.

García Cancilini, N. (1982): Las culturas populares en el capitalismo, Casa de las Américas, La Habana.

- (1990): Culturas bibridas. Estrategias para entrar y salir de la modernidad, Ed. Grijalbo, México.

Gliertz, C. (1987): La interpretación de las culturas (1973), Gedisa Editorial, México.

Gramsci, A. (1974): Antología, a cargo de M. Sacristán, Siglo XXI, México.

- (1977): Cultura y Literatura (1953), Ed. Península, Barcelona. 
Gunciotor Y Sierra, A. (1984): Noticia bistórica del Folklore (1922), Instituto de Cultura Andaluza, Sevilla.

Hobsiawn, E., y Rangile, T. (1983): The Invention of Tradition, University Press, Cambridge. Hoyos Sainz, L., y Hoyos Sancho, N. (1947): Manual de Folklore, Revista de Occidente, Madrid.

IMBERT, M. (1979): «Les cultures populaires: sous-produits culturels ou cultures marginalisées?», en G. PuYol y R. LABourie, Les culture's populaires, Edouard Privat, editeur, Toulouse, pp. 13-21.

Lombardi Satriani, L. M. (1978): Apropiación y destrucción de la cultura de las clases subalternas (1973), Editorial Nueva Imagen, México.

Ma(HAD), A. (1981): Director de El Folklore Andaluz, 1882-1883. Reproducción en Editorial Tres, Catorce, Diecisiete, Madrid.

Martin-Barbero, J. (1987): De los medios a las mediaciones. Comunicación, cultura y begemonía, Ediciones G. Gili, México.

Muchembled, R. (1978): Culture populaire et culture des élites, Flammarion, París.

Passeron, J. C., y Gricinon, C. (1982): Sociologie de la culture et sociologie des cultures populaires, Documents du Gides, Paris.

Shiachi, M. (1989): Discourse on Popular Culture, Stanford University Press, Stanford.

Velasc(o, H. M. (1990): «El Folklore y sus paradojas», Rlivista Española de InVESTICiACiones SOCHOLOGICAs, 49, enero-marzo, pp. 123-144.

Williams, R. (1976): Keywords. A Vocabulary of Culture and Society, Oxford University Press, New York. 